\title{
Hypoxic and Normoxic-Human Wharton's Jelly Mesenchymal Stem Cell-Free Lysate for Anticancer Therapies
}

\author{
Wahyu WIDOWATI ${ }^{1}{ }^{* *}$, Diana Krisanti JASAPUTRA ${ }^{1}$, \\ Hanna Sari Widya KUSUMA ${ }^{2}$, Rizal RIZAL ${ }^{2,3}$, Dian Ratih LAKSMITAWATI ${ }^{4}$, \\ Dwi Surya ARTIE ${ }^{2}$, Ika Adhani SHOLIHAH ${ }^{2}$, Dewani Tediana YUSEPANY ${ }^{2}$, \\ Riyani LESTARI ${ }^{2}$, Rr. Anisa Siwianti HANDAYANI' ${ }^{2}$, Seila ARUMWARDANA², \\ Harry MURTI ${ }^{5}$, Indra BACHTIAR ${ }^{5}$ and Mawar SUBANGKIT ${ }^{6}$
}

${ }^{I}$ Faculty of Medicine, Maranatha Christian University, Bandung 40164, West Java, Indonesia

${ }^{2}$ Biomolecular and Biomedical Research Center, Aretha Medika Utama, Bandung 40163, Indonesia

${ }^{3}$ Biomedical Engineering, Department of Electrical Engineering, Faculty of Engineering, Universitas Indonesia, Depok 16424, West Java, Indonesia

${ }^{4}$ Faculty of Pharmacy, University of Pancasila, Jakarta 12640, Indonesia

${ }^{5}$ Stem Cell and Cancer Institute, Jakarta 13210, Indonesia

${ }^{6}$ Laboratory of Veterinary Pathology, Faculty of Veterinary Medicine, IPB University,

Bogor 16680, West Java, Indonesia

('Corresponding author's e-mail: wahyu_w60@yahoo.com)

Received: 20 December 2019, Revised: 21 June 2020, Accepted: 22 July 2020

\begin{abstract}
Cancer can be defined as a disease in which a group of uncontrolled cells growth by ignoring the rules of normal cell division. Mesenchymal Stem Cells (MSCs) are one of the promising cell-based therapies for anticancer therapies. Preceding research had disclosed that conditioned medium from hypoxic-treated human Wharton's jelly mesenchymal stem cells (hWJMSCs-hypoCM) and normoxictreated hWJMSCs (hWJMSCs-norCM) can inhibit the proliferation of various cancer cell lines and have no cytotoxic effect on normal cells. The present study, hence, measured the effect of a human Wharton's jelly stem cells cell-free lysate (hWJMSCs-CL), cultured with hypoxic condition (hWJMSCs-hypoCL), and normoxic condition (hWJMSCs-norCL) towards several cancer cell lines including ovarian (SKOV3), cervical (HeLa), tongue squamosa (HSC3), and liver (HepG2) proliferation. Human mesenchymal stem cells (hMSCs), human fibroblast cells, and mouse fibroblast cells (NIH3T3) were used as control. Both hWJMSCs-CL grown in hypoxic and normoxic conditions could inhibit the proliferation of various cancer cell lines with median inhibitory concentration $\left(\mathrm{IC}_{50}\right) 21.09-95.92 \mu \mathrm{g} / \mathrm{mL}$ and could cause low inhibition of the normal cells with $\mathrm{IC}_{50} 409.19-799.74 \mu \mathrm{g} / \mathrm{mL}$. The hWJMSCshypoCL and hWJMSC-norCL could inhibit various cancer and were not harmful to normal cells.
\end{abstract}

Keywords: Anticancer, Cell-free lysate, Hypoxia, Mesenchymal stem cells, Wharton's jelly

\section{Introduction}

Cancer can be defined as a disease caused by the uncontrolled growth of a cluster of cells [1]. Various types of therapies for cancer have been found, such as chemotherapy, surgery, and radiotherapy [2]. However, treatment-related side effects and drug resistance limit the efficacies of many therapeutic options. Researchers are working to develop new therapies with low toxicity to normal cells but effective to kill/ inhibit cancer cells. Cell-based therapy has now become one of the most explored treatments. One of the pledging cell-based therapies in stem cells is the application of Mesenchymal Stem Cells (MSCs).

Walailak J Sci \& Tech 2021; 18(9): 9270 
http://wjst.wu.ac.th

The MSCs are easily isolated and propagated in vitro and applied widely in the treatment of different cancers [3]. One pivotal source of MSCs is the umbilical cords' Wharton's jelly. The MSCs have several unique characteristics, including high expression of cluster of differentiation (CD) CD73, CD90, and CD105; short doubling time; low expression of CD34, CD14, CD45 and HLA-II; and able to differentiate into osteocytes, chondrocytes, and adipocytes [4].

Cell culture conditions, e.g., oxygenation, can affect MSCs proliferation [4]. Previous studies had shown that incubation on normoxic tension affected hWJMSCs characteristics at late and early passage, in contrast, hypoxic tension can increase the MSCs proliferation without affecting surface markers [4-6]. Previous studies discovered that hWJMSCs cell lysate (hWJMSCs-CL) could inhibit the growth of cancer cells such as ovarian carcinoma (TOV-112D), breast adenocarcinoma (MDA-MB-231), and osteosarcoma (MG-63) cells [7]. In the current study, the aim was to measure the hWJMSCs, cell-free lysate cultured with hypoxia-treated hWJMSCs (hWJMSCs-hypoCL), and normoxia (hWJMSCs-norCL) for anticancer therapies toward cancer cell lines, involving HSC3, HepG2, HeLa, SKOV3, hMSCs, human fibroblast cells (normal cell), and NIH3T3.

\section{Materials and methods}

\section{Isolation and cultivation of hWJMSCs}

Isolation: Umbilical Cords (UC) were collected freshly from conceiving women (age: 25 - 40) in Immanuel Hospital, Bandung, Indonesia. This research had been approved by the Institutional Ethics Committee at the Stem Cell and Cancer Institute, Jakarta, Indonesia, and from the Institutional Ethics Committee collaboration between Immanuel Hospital Bandung, Bandung, Indonesia, and Maranatha Christian University, Bandung, Indonesia number 12/KEP FK UKM-RSI/III/2013 [4,6].

Cultivation: UC were washed by phosphate buffer saline (PBS) and cut into $1-2 \mathrm{~mm}$. The explants were cultured in MEM- $\alpha$ with 2 mM GlutaMax (Gibco, 32561037, Massachusetts, USA), supplemented with $20 \%$ fetal bovine serum (FBS) (Gibco,10270106, Massachusetts, USA) and added with penicillinstreptomycin (Gibco, 15140122, Massachusetts, USA), amphotericin B (Gibco, 15290018, Massachusetts, USA). Cultures were incubated in a humidified atmosphere with $5 \% \mathrm{CO}_{2}$ at $37{ }^{\circ} \mathrm{C}$ for 3 weeks. The mediums were replaced every 5 days. When cultures had reached $80-90 \%$ confluency, cells were harvested and divided into 2 plates at $8 \times 10^{3}$ cells $/ \mathrm{cm}^{2}$ density. First plate was cultured in normoxic condition $\left(95 \%\right.$ air $\left.\left(21 \% \mathrm{O}_{2}\right) / 5 \% \mathrm{CO}_{2}\right)$ and $2^{\text {nd }}$ plate in hypoxic condition $\left(5\right.$ and $\left.2.5 \% \mathrm{O}_{2}\right)[4,6]$.

\section{Phenotype characterization of hWJMSCs}

Passage 4 of the hWJ-MSCs was characterized for CD19, CD34, CD45, CD73, CD90, CD105, CD145, and HLA-II expression using a flow cytometer. The hWJMSCs were harvested at $80 \%$ confluence and dissociated using trypsin-EDTA and centrifuged at $300 \mathrm{~g}$ for $10 \mathrm{~min}$. The pellet was resuspended using $2 \%$ FBS + PBS and cells were counted using a hemocytometer. Between $100-200$ cells in $25 \mathrm{~mL}$ PBS were put into flow cytometer FACS (BD FACS Calibur ${ }^{\mathrm{TM}}$ ) tubes. The antibody was added to each FACS tube pursued by incubation at $4{ }^{\circ} \mathrm{C}$ for $15 \mathrm{~min}$. Results were analyzed in Cell Quest Pro Acquisition on the BD FACStation ${ }^{\mathrm{TM}}$ software. Each measurement was done with 3 replications $[4,6]$.

Trilineage differentiation character of hWJMSCs was done with the following steps. Osteogenic differentiation: hHWJMSCs (P4) at $1 \times 10^{4}$ cells $\mathrm{cm}^{-2}$ density were cultured in StemPro Osteogenesis Differentiation Kit (Gibco, A10072-01, Massachusetts, USA) for 3 weeks. Calcium deposits were visualized with Alizarin red S (Amresco, 9436, Pennsylvania, USA). Chondrogenic differentiation: hWJMSCs at $1 \times 10^{4}$ cells $\mathrm{cm}^{-2}$ density were cultured in StemPro Chondrogenesis Differentiation Kit (Gibco A10071-01, Massachusetts, USA) for 2 weeks. The extracellular matrix deposits were visualized with Alcian blue (Amresco, 0298, Pennsylvania, USA). Adipogenic differentiation: hWJMSCs were cultured at $1 \times 10^{4}$ cells $\mathrm{cm}^{-2}$ density in Adipogenesis Differentiation Kit (Gibco, A10070-01, Massachusetts, USA) for 2 weeks. Lipid droplets were confirmed using Red O (Sigma Aldrich, 00625, Missouri, USA) [8-10]. 
Preparation of cell free lysate from hypoxia-treated hWJMSCs (hWJMSCs-hypoCL) and normoxia-treated hWJMSCs (hWJMSCs-norCL)

Cell-free lysates were obtained using 2-D Rehydration and Tributylphosphine (TBP) reducing agent (BioRad, 163-2086, California, USA). Harvested hWJMSCs were centrifuged at $500 \mathrm{~g}$ for $4 \mathrm{~min}$ and the pellets were suspended in a mix solution $(1 \mathrm{~mL} 2-\mathrm{D}$ Rehydration $+10 \mu \mathrm{L}$ TBP $)$. The cells were, then, sonicated at $28^{\circ} \mathrm{C}$ for $30 \mathrm{sec} 4$ times. Then, the mixture was centrifuged at $16,000 \mathrm{~g}$ and $20{ }^{\circ} \mathrm{C}$ for $30 \mathrm{~min}$. The supernatant, pellets were stored at $-80^{\circ} \mathrm{C}$ for further use [9].

\section{Cultivation of cancer and normal cells}

Liver (HepG2-ATCC® HB-8065 ${ }^{\mathrm{TM}}$ ), cervical (HeLa-ATCC® CCL-2 ${ }^{\mathrm{TM}}$ ), tongue squamous (HSC3ATCC, Manassas, VA), ovarian (SKOV3-ATCC $®$ HTB-77TM) cancer cell lines and normal cells such as mouse fibroblast (NIH3T3-ATCC® CRL-1658 ${ }^{\mathrm{TM}}$ ), hMSCs (primary cells from Wharton's Jelly), human fibroblast (primary cells) were obtained from Stem Cell and Cancer Institute, Jakarta Indonesia. Liver and cervical cells were maintained, and grown in Eagle's Minimum Essential Medium (MEM, Biowest, L0416-500, France), ovarian cells were maintained and grown in McCoy's 5a Medium Modified (Biowest, L0210-500, France), mouse fibroblast cells were maintained and grown in Dulbecco modified Eagle's medium (DMEM, Biowest, L0101-500, France) with $10 \%$ FBS (Sigma Aldrich, F9665, Missouri, USA), penicillin-streptomycin (Gibco, 15140122, Massachusetts, USA). The cells were incubated in a humidified atmosphere at $37^{\circ} \mathrm{C}$ and $5 \% \mathrm{CO}_{2}[4,6,11]$.

\section{Cell treatments and viability assay}

Cells were seeded at $5 \times 10^{3}$ density in 96 -well plates with growth mediums according to the cell types as mentioned before and incubated at $37^{\circ} \mathrm{C} 5 \% \mathrm{CO}_{2}$ condition for $24 \mathrm{~h}$. hWJMSCs from normoxic and hypoxic condition cell lysates (hWJMSCs-norCL and hWJMSCs-hypoCL) in various concentrations $(0,5,10$, and $15 \mu \mathrm{g} / \mathrm{mL})$ were later added. Oxygen level for the normoxic and hypoxic condition were 2.5 and $5 \%$. Cultures were later incubated for $72 \mathrm{~h}[6,11,12]$. Anticancer activity as indicated with viability was measured using tetrazolium compound [3-(4,5-dimethylthiazol-2-yl)-5-(3-carboxymethoxyphenyl)-2(4-sulfophenyl)-2H-tetrazolium, inner salt (MTS) assay (Promega, G3581, Madison, USA). MTS was added at $10 \mu \mathrm{L}$ to each well. The plate was incubated at $5 \% \mathrm{CO}_{2}, 37{ }^{\circ} \mathrm{C}$ for $4 \mathrm{~h}$. The $490 \mathrm{~nm}$ absorbance was measured using microplate reader (Multiskan Go, Thermo Scientific Inc, USA) [6].

\section{Statistical analysis}

Statistical analysis was performed with Statistical Package for the Social Sciences (SPSS) statistics version 20.0 software. The cell number, viability, and proliferation inhibition in cancer cell lines and in normal cells were calculated, expressed in means and standard deviation (Mean \pm STD). Analysis of variance (ANOVA) was performed to the significant difference among treatments at $95 \%$ confidence interval. Tukey's HSD post hoc test was performed on different treatment concentrations.

\section{Results and discussion}

The hWJMSCs under both hypoxic and normoxic condition displayed the negative expression for CD14, CD19, CD34, CD45, and HLA-II and positive expression for CD73, CD90, CD105 in early (P4) and later (P8) passage (Table 1). The hWJMSCs also depicted tri-lineage differentiation (chondrogenic, adipogenic, osteogenic) in both hypoxic and normoxic condition (data/photo not shown). The hypoxic or normoxic condition did not affect hWJMSCs characteristics, which was also stable in a later passage. 
http://wjst.wu.ac.th

Table 1 Effects of the oxygen level and type of passage toward the surface marker of hWJMSCs.

\begin{tabular}{|c|c|c|c|c|c|c|c|c|c|}
\hline Passage & $\mathrm{O}_{2}$ level & CD14 (\%) & CD19 (\%) & CD34 (\%) & CD45 (\%) & CD73 (\%) & CD90 (\%) & CD105 (\%) & HLA-II (\%) \\
\hline \multirow[t]{3}{*}{$\mathrm{P} 4$} & Normoxia & $0.00 \pm 0.01$ & $-0.39 \pm 1.12$ & $0.00 \pm 0.00$ & $0.00 \pm 0.00$ & $96.67 \pm 2.25$ & $96.17 \pm 1.00$ & $96.00 \pm 1.39$ & 0.2 \\
\hline & & & & 05 & & 25 & 71 & & \\
\hline & $\mathrm{Hy}$ & -0.4 & 0.5 & .51 & -0.0 & 10 & 13 & 94. & .56 \\
\hline \multirow[t]{3}{*}{ P8 } & & 0.00 & -0.7 & 0.0 & 0.0 & 11 & 76 & & 00 \\
\hline & Нур & $0.00=$ & 0.15 & $0.00=$ & 0.00 & 97.6 & .95 & 95. & 0.0 \\
\hline & Нурохіа $2.5 \%$ & $-0.51 \pm 0.76$ & $0.50 \pm 0.87$ & $-0.26 \pm 0.32$ & $0.02 \pm 0.09$ & $96.21 \pm 4.11$ & $91.74 \pm 0.00$ & $93.23 \pm 4.11$ & $-2.84 \pm 2.82$ \\
\hline
\end{tabular}

hWJMSCs-hypoCL and hWJMSCs-norCL could inhibit the proliferation of cancer cells significantly compared to control. Based on Figure 1, the concentration of cell lysate $15 \mu \mathrm{g} / \mathrm{mL}$ had the highest proliferation inhibition to HepG2 cells. The most active of hWJMSC-hypoCL and hWJMSCnorCL inhibited liver cancer cells (HepG2). Both hWJMSC-hypoCL and hWJMSC-norCL have similar anticancer activity.

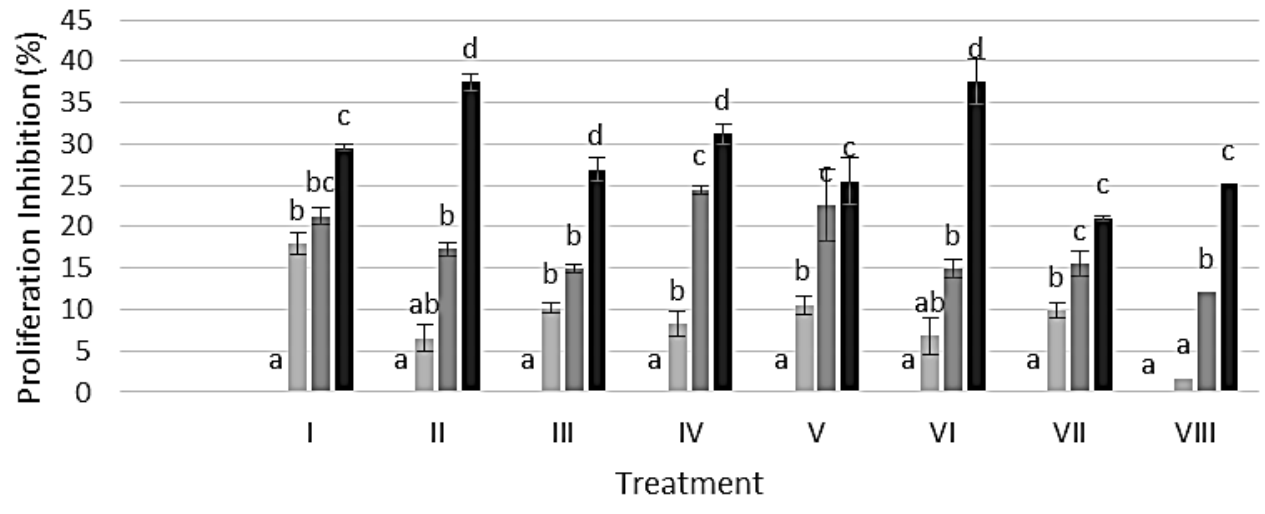

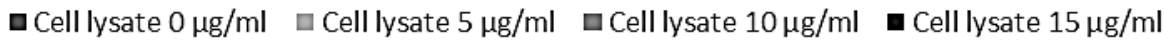

Figure 1 Effect of hWJMSCs-hypoCL and hWJMSCs-norCL toward proliferation inhibition of HeLa, HepG2, SKOV3, HSC3 cancer cells.

*(I) Hypoxia-HeLa, (II) Hypoxia-HepG2, (III) Hypoxia-SKOV3, (IV) Hypoxia-HSC3, (V) NormoxiaHeLa, (VI) Normoxia-HepG2, (VII) Normoxia-SKOV3, (VIII) Normoxia-HSC3. The data of cell proliferation inhibition are presented as a histogram of Mean $\pm \mathrm{STD}$, different letters in the same group treatment with various levels of hWJMSCs-CL are significant differences among concentrations at $p<$ 0.05 (Tukey HSD Post Hoc test). HeLa: Cervical cancer, HSC3: Tounge squamous cancer, HepG2: Liver cancer, SKOV3: Ovarian cancer.

The most active of cell lysate were hWJMSCs-hypoCL and hWJMSCs-norCL toward HepG2 cells, HSC3 cells. The hWJMSCs-norCL was lowest anticancer activity toward SKOV3 $\left(\mathrm{IC}_{50}=95.93 \mu \mathrm{g} / \mathrm{mL}\right)$ and hWJMSCs-hypoCL was lowest anticancer activity toward HeLa cells $\left(\mathrm{IC}_{50}=86.90 \mu \mathrm{g} / \mathrm{mL}\right) \mathrm{can}$ be seen on Table 2. 
http://wjst.wu.ac.th

Table 2 The $\mathrm{IC}_{50}$ of hWJMSCs-hypoCL and hWJMSCs-norCL in various cancer cell lines.

\begin{tabular}{lcc}
\hline \multirow{2}{*}{ Cancer cell lines } & \multicolumn{2}{c}{ IC $_{\mathbf{5 0}}$ value $(\boldsymbol{\mu g} / \mathbf{m L})$} \\
\cline { 2 - 3 } & hWJMSCs-norCL & hWJMSCs-hypoCL \\
\hline HeLa & 22.69 & 86.90 \\
HepG2 & 21.71 & 21.09 \\
SKOV3 & 95.93 & 46.79 \\
HSC3 & 24.80 & 33.46 \\
\hline
\end{tabular}

The effect of hWJMSCs-hypoCL and hWJMSCs-norCL toward human, mouse fibroblast cells, hMSCs can be seen at Figure 2. Figure 2 described that normal cells, such as NIH3T3, hMSCs, and human fibroblast treated with hWJMSC-hypoCL and hWJMSC-norCL with various concentrations $(0,5$, $10,15 \mu \mathrm{g} / \mathrm{mL})$, resulted low $(<10 \%$ ) proliferation inhibition compared with control. Cell lysate both hWJMSC-hypoCL and hWJMSC-norCL were not toxic toward normal cells.

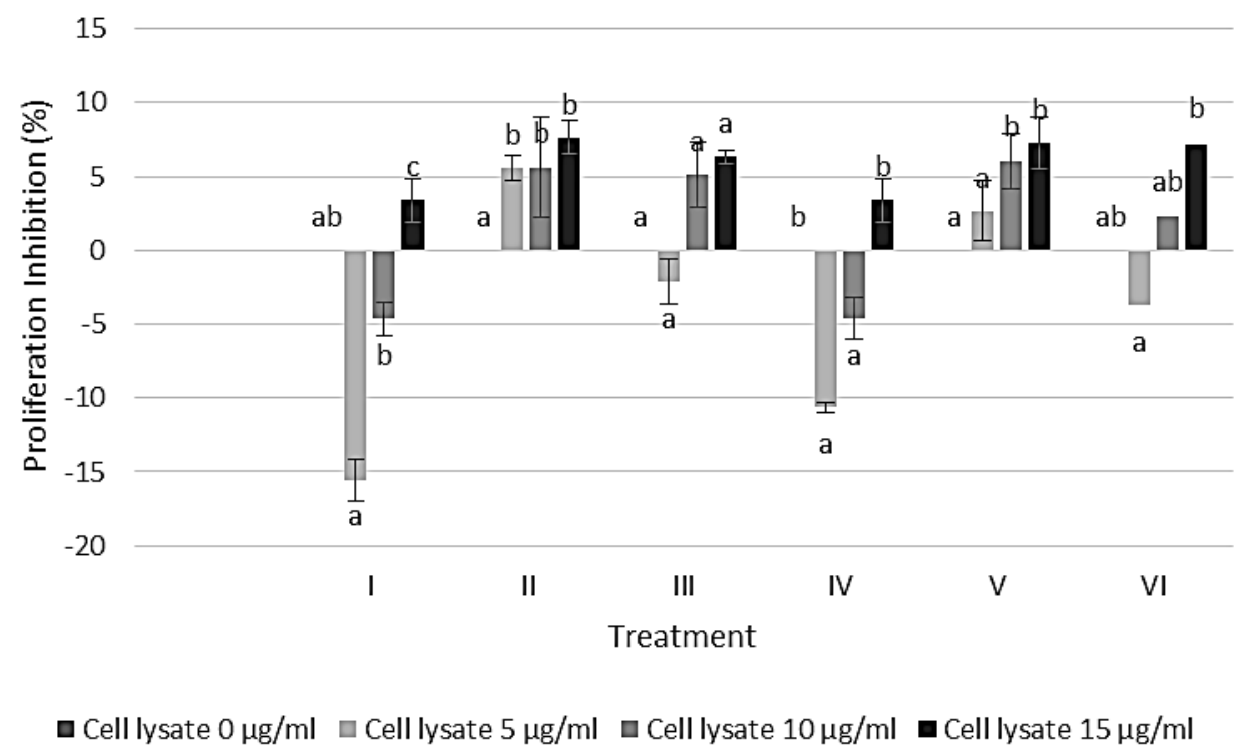

Figure 2 Effect of hWJMSCs-hypoCL and hWJMSCs-norCL toward proliferation inhibition of normal cells.

*(I) Hypoxia-NIH3T3, (II) Hypoxia-Human Fibroblast, (III) Hypoxia-hMSCs, (IV) Normoxia-NIH3T3, (V) Normoxia-Human Fibroblast, (VI) Normoxia-hMSCs. The data of cell proliferation inhibition are presented as a histogram of Mean $\pm \mathrm{SD}$, different letters in the same group treatment with various levels of hWJMSCs-CL are significant differences among concentrations at $p<0.05$ (Tukey HSD Post Hoc test). NIH3T3: Mouse fibroblast, hMSCs: human Mesenchymal Stem Cells.

Based on the high value of $\mathrm{IC}_{50}$, it was considered that cell lysate was safe, not toxic toward normal cells. The unlimited value of $\mathrm{IC}_{50}$ toward NIH3T3 cells can be seen in Table 3 . 
Table 3 The $\mathrm{IC}_{50}$ of hWJMSCs-hypoCL and hWJMSCs-norCL in various normal cells.

\begin{tabular}{lcc}
\hline \multirow{2}{*}{ Normal cells } & \multicolumn{2}{c}{ IC $_{\mathbf{5 0}}$ value $(\boldsymbol{\mu g} / \mathbf{m L})$} \\
\cline { 2 - 3 } & hWJMSCs-norCL & hWJMSCs-hypoCL \\
\hline NIH3T3 & - & - \\
Human fibroblast & 409.19 & $629,799.74$ \\
hMSCs & 468.28 & $4,860.85$ \\
\hline
\end{tabular}

$* \mathrm{IC}_{50}=$ median inhibitory concentration; hWJMSCs: human Wharton's Jelly Mesenchymal Stem Cells; hWJMSCs-hypoCL: hypoxia-treated hWJMSCs cell lysate, hWJMSCs-norCL: normoxia-treated hWJMSCs cell lysate.

The hMSCs have a high potential that is used as a therapeutic agent for clinical studies. The hWJMSCs is the best source of hMSCs that can be used clinically. Besides, recent research findings revealed that WJ is the best source of stem cells among other compartments of the UC [13]. The surface markers of hWJMSCs in hypoxic and normoxic conditions were not significantly different $[4,6]$.

The cell lysate of hWJMSCs (hWJMSCs-CL) in the treatment of hypoxia $5 \%$ (hWJMSCs-hypoCL) and normoxia (hWJMSCs-norCL) from passage 4 (P4) has anticancer activity in various cancer cells including HeLa, SKOV3, HSC3, HepG2 cancer cells and not toxic to normal cells including NIH3T3, human fibroblasts, and hMSCs.

The MSCs have an antitumor activity intermediator by paracrine resulted in damaged Endothelial Progenitor Cells (EPCs) downregulation proangiogenic factor including Platelet-Derived Growth Factor (PDGF-BB), Fibroblast Growth Factor-2 (FGF-2), Insulin Growth Factor (IGF-1), and interleukin-1 $\beta$ (IL13) [14]. Paracrine secretions of hWJMSCs-CL, contain various factors, including cytokines which were able to trigger tumor cell apoptosis [6].

Human WJMSCs (hWJMSCs) inhibits the proliferation of solid tumors such as osteosarcoma, ovarian carcinoma, and mammary carcinoma [13]. Cell lysate significantly down-regulated the expression of TAF (TBP-associated factor) in keloid cells [14]. Cell lysate was collected from hWJMSCs culture at early passages (P3 to P7) resulted in increasing cell death in breast adenocarcinoma cells (MDA-MB231), osteosarcoma cells (MG-63) and while no toxicity was observed in the case of a normal human fibroblast cell line (CDE-112sk) [7]. The secretome in hWJMSCs was measured including IL-1 $\alpha$, IL-6, IL-8, and Vascular Endothelial Growth Factor (VEGF) in both of normoxic and hypoxic oxygen tension, in early (P4) and late passage (P8) [15], which the secretome of hWJMSCs have anticancer activity toward various cancer cell line [6].

The hWJMSCs secretome can upregulate pro-apoptotic genes. The increased cell death was observed at sub-G1/S and proliferation was observed at the G2/M phase of the mitotic cycle [13]. Tumor suppressor cells and upregulation of several pro-apoptotic in hWJMSCs involving several cytokines in cell (IL-12a), which inducing apoptosis and thus mediate the anticancer effects of hWJMSCs-CL [16,17]. Anti-inflammatory IL-6 observed in the conditioned medium of hWJMSCs (hWJMSCs-CM) has promise anticancer. Anti-inflammatory agents can alter the tumor themselves, the tumor microenvironment, induce apoptosis, decrease cancer cell migration, and increase sensitivity to other therapies or simultaneous therapies [6,15]. Tumor-producing factors (chemokines, cytokines, growth factors, and angiogenic) have overlapping functions in promoting tumor growth [18]. Bone Marrow Mesenchymal Stem Cells (BMMSCs) under hypoxic conditions and their fractions showed that the stem cells expressed and secreted significant IL-6 and IL-8 [19], hWJMSCs both hypoxic and normoxic condition secreted IL6 , IL-8 which can kill cancer cells $[6,7,15]$. Survival of mice containing lymphoma through induction of endothelial cell (EC) apoptosis could be increased after intraperitoneal MSCs injection [12,20]. The most effective cell lysate treatment for cancer inhibition was treated with normoxia (hWJMSCs-norCL) 
http://wjst.wu.ac.th

compared to hypoxia (hWJMSCs-hypoCL), in the previous study, it was shown that hWJMSCs-norCM had higher anticancer compared to hWJMSCs-hypoCM [6].

The hWJSC-CL treatment to osteosarcoma (SKES-1 and MG-63) cells showed significant decreases in cell proliferation. The pro-apoptotic gene (BAX) was increased, the autophagy-related ATG-5 and BECLIN-1 genes were increased, the anti-apoptotic BCL2 and SURVIVIN genes were decreased both in MG-63 and SKES-1 cells treated with hWJSC-CM and hWJSC-CL [21]. A previous study showed that a hypoxic environment could greatly improve the expression of chemokine receptors during in vitro expansion and eventually increased the efficiency of MSCs-based regenerative therapies [22]. The hWJMSCs-hypoCL and hWJMSCs-norCL were able to inhibit various cancer including HSC3, HeLa, SKOV3, HepG2, and not toxic for normal cells. The hWJMSCs-norCL and hWJMSCs-hypoCL could inhibit proliferation of various cancer cell lines with $\mathrm{IC}_{50} 21.09-95.93 \mu \mathrm{g} / \mathrm{mL}$ and exhibited low inhibition toward normal cells with $\mathrm{IC}_{50} 409.19 \mu \mathrm{g} / \mathrm{mL}$ up to unlimited value.

\section{Conclusions}

The experiments in this study had uncovered that hWJ-MSCs-hypoCL and hWJ-MSCs-norCL could inhibit various cancer cell lines and were not toxic for normal cells.

\section{Acknowledgements}

The authors gratefully acknowledge the financial support from Insinas Riset Individu Pratama (2013 - 2015), the Ministry of Research, Technology and Higher Education of the Republic of Indonesia. Our research was supported by the Stem Cell and Cancer Institute, Jakarta, Indonesia, and Biomolecular and Biomedical Research Center, Aretha Medika Utama, Bandung, Indonesia both research methodology and facilities.

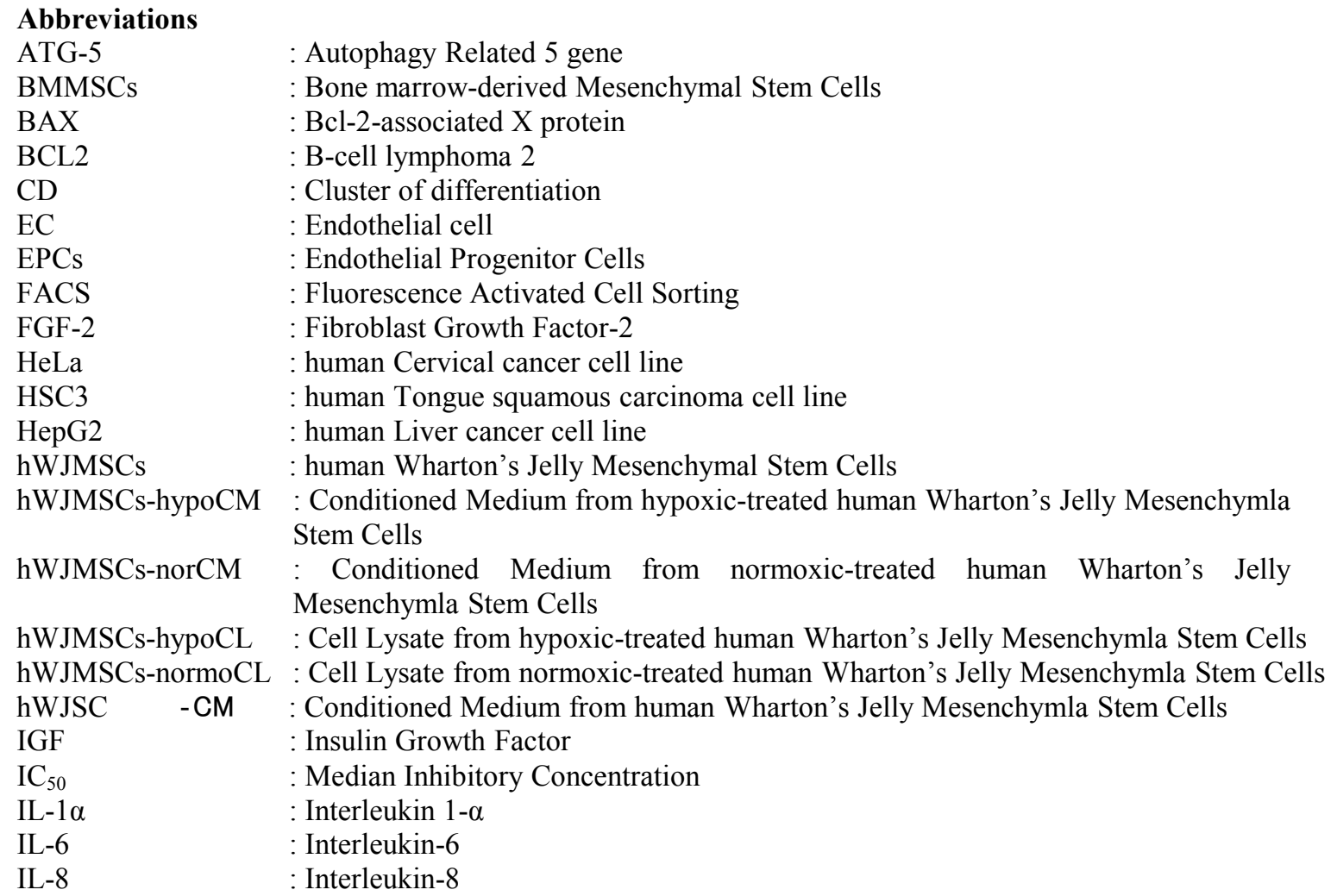




$\begin{array}{ll}\text { IL-12a } & \text { : Interleukin 12-a } \\ \text { MDA-MB-231 } & \text { : human Breast adenocarcinoma cell line } \\ \text { MSCs } & \text { : Mesenchymal Stem Cells } \\ \text { MG 36 } & \text { : human Osteosarcoma cell line } \\ \text { NIH3T3 } & : \text { mouse Fibroblast cell line } \\ \text { PDGF } & : \text { Platelet-Derived Growth Factor } \\ \text { SKOV3 } & : \text { human Ovarian cancer cell line } \\ \text { SKES-1 } & \text { : human Osteosarcoma cell line } \\ \text { TBP } & : \text { Tributylphosphine } \\ \text { TOV-112D } & : \text { Ovarian cancer cell line } \\ \text { UC } & : \text { Umbilical Cord } \\ \text { VEGF } & : \text { Vascular Endothelial Growth Factor }\end{array}$

\section{References}

[1] Hejmadi M. Introduction to Cancer Biology. $2^{\text {nd }}$ ed. BoonBooks.com, Frederiksberg, Denmark, 2010.

[2] M Arruebo, N Vilaboa, B Sáez-Gutierrez, J Lambea, A Tres, M Valladares and A GonzálezFernández. Assessment of the evolution of cancer treatment therapies. Cancers 2011; 3, 3279-30.

[3] CL Zhang, T Huang, BL Wu, WX He and D Liu. Stem cells in cancer therapy: Opportunities and challenges. Oncotarget 2017; 8, 75756-66.

[4] W Widowati, L Wijaya, I Bachtiar, RF Gunanegara, SU Sugeng, YA Irawan, SB Sumitro and MA Widodo. Effect of oxygen tension on proliferation and characteristics of Wharton's jelly-derived mesenchymal stem cells. Biomark. Genom. Med. 2014; 6, 43-8.

[5] U Nekanti, S Dastidar, P Venugopal, S Totey and M Ta. Increased proliferation and analysis of differential gene expression in human Wharton's jelly-derived mesenchymal stromal cells under hypoxia. Int. J. Biol. Sci. 2010; 6, 499-512.

[6] W Widowati, L Wijaya, H Murti, H Widyastuti, D Agustina, DR Laksmitawati, N Fauziah, SB Sumitro, MA Widodo and I Bachtiar. Conditioned medium from normoxia (WJMSCs-norCM) and hypoxia-treated WJMSCs (WJMSCs-hypoCM) in inhibiting cancer cell proliferation. Biomark. Genom. Med. 2015; 7, 8-17.

[7] K Gauthaman, FC Yee, S Cheyyatraivendran, A Biswas, M Choolani and A Bongso. Human umbilical cord Wharton's jelly stem cell (hWJSC) extracts inhibit cancer cell growth in vitro. $J$. Cell. Bichem. 2012; 113, 2027-39.

[8] EK Jun, Q Zhang, BS Yoon, JH Moon, G Lee, G Park, PJ Kang, JH Lee, A Kim and S You. Hypoxic conditioned medium from human amniotic fluid-derived mesenchymal stem cells accelerates skin wound healing through TGF- $\beta$ /SMAD2 and PI3K/Akt pathways. Int. J. Mol. Cell. Sci. 2014; 15, 605-28.

[9] L Zheng, D Zhang, X Chen, L Yang, Y Wei and X Zhao. Antitumor activities of human placentaderived mesenchymal stem cells expressing endostatin on ovarian cancer. PloS One 2012; 7 , e39119.

[10] M Dominici, KL Blanc, I Mueller, I Slaper-Cortenbach, F Marini, D Krause, R Deans, A Keating, D Prockop and E Horwitz. Minimal criteria for defining multipotent mesenchymal stromal cells. The International Society for Cellular Therapy position statement. Cytotherapy 2006; 8, 315-7.

[11] A Subramanian, CY Fong, A Biswas and A Bongso. Comparative characterization of cells from the various compartments of the human umbilical cord shows that the Wharton's jelly compartment provides the best source of clinically utilizable mesenchymal stem cells. PloS One 2015; 10, e0127992.

[12] IAW Ho, HC Toh, WH Ng, YL Teo, CM Guo, KM Hui and PYP Lam. Human bone marrowderived mesenchymal stem cells suppress human glioma growth through inhibition of angiogenesis. Stem Cells 2013; 31, 146-55. 
http://wjst.wu.ac.th

[13] HD Lin, CY Fong, A Biswas, M Choolani and A Bongso. Human Wharton's jelly stem cells, its conditioned medium and cell-free lysate inhibit the growth of human lymphoma cells. Stem Cell Rev. Rep. 2014; 10, 573-86.

[14] CY Fong, A Biswas, A Subramanian, A Srinivasan, M Choolani and A Bongso. Human keloid cell characterization and inhibition of growth with human Wharton's jelly stem cell extracts. J. Cell. Biochem. 2014; 115, 826-38.

[15] W Widowati, H Widyastuti, H Murti, DR Laksmitawati, HS Kusuma, R Rizal, E Afifah, SB Sumitro, MA Widodo and I Bachtiar. Interleukins and VEGF secretome of human Wharton's jelly mesenchymal stem cells-conditioned medium (hWJMSCs-CM) in different passages and oxygen tensions. Biosci. Res. 2017; 14, 776-87.

[16] M Kobayashi, L Fitz, M Ryan, RM Hewick, SC Clark, S Chan, R Loudon, F Sherman, B Perussia and G Trinchieri. Identification and purification of natural killer cell stimulatory factor (NKSF), a cytokine with mutiple biologic effect on human lymphocytes. J. Exp. Med. 1989; 170, 827-45.

[17] SF Wolf, PA Temple, M Kobayashi, D Young, M Dicig, L Lowe, R Dzialo, L Fitz, C Ferenz and RM Hewick. Cloning of cDNA for natural killer cell stimulatory factor, a heterodimeric cytokine with multiple biologic effects on T and natural killer cells. J. Immunol. 1991; 146, 3074-81.

[18] V Levina, Y Su, B Nolen, X Liu, Y Gordin, M Lee, A Lokshin and E Gorelik. Chemotherapeutic drugs and human tumor cells cytokine network. Int. J. Cancer 2008; 123, 2031-40.

[19] L Chen, Y Xu, J Zhao, Z Zhang, R Yang, J Xie, J Xie, X Lui and S Qi. Conditioned medium from hypoxic bone marrow-derived mesenchymal stem cells enhances wound healing in mice. PloS One 2014; 9, e96161.

[20] K Otsu, S Das, SD Houser, SK Quadri, S Bhattacharya and J Bhattacharya. Concentrationdependent inhibition of angiogenesis by mesenchymal stem cells. Blood 2009; 113, 4197-205.

[21] K Gauthaman, CY Fong, S Arularasu, A Subramanian, A Biswas, M Choolani and A Bongso. Human Wharton's jelly stem cell conditioned medium and cell-free lysate inhibit human osteosarcoma and mammary carcinoma cell growth in vitro and in xenograft mice. J. Cell. Biochem. 2013; 114, 366-77.

[22] N Haque, MT Rahman, AKN Hayaty and AM Alabsi. Hypoxic culture conditions as a solution for mesenchymal stem cell based regenerative therapy. Sci. World J. 2013; 2013, 1-12. 